Side of origin of 264 cases of epithelial ovarian cancer

\begin{tabular}{ll}
\hline Side & No $(\%)$ \\
\hline Unilateral: & \\
Right & $98(37)$ \\
Left & $94(36)$ \\
Bilateral: & $43(16)$ \\
$\quad$ Right dominant & $29(11)$ \\
$\quad$ Left dominant & \\
Total & $141(53)$ \\
$\quad$ Right & $123(47)$ \\
Left &
\end{tabular}

hospitals: Beth Israel, Newton-Wellesley, Mount Auburn, and Massachusetts General Hospitals, Boston; Memorial Sloan-Kettering Medical Center, New York, and Lennox Hill Hospitals, New York; University of Pennsylvania, Hahnemann, Lankenau, Medical College of Pennsylvania, Montgomery, Pennsylvania, Presbyterian, and Thomas Jefferson Hospitals, Philadelphia; and Johns Hopkins Hospital, Baltimore. Supported by contracts 223-76-3016, 223-80-3001, and 226-82-0007 and cooperative agreements UO1 FD01222 and FD-U-000082 from the Food and Drug Administration and by grant 5 R37 CA45762 from the National Cancer Institute.
1 Fathalla MF. Incessant ovulation-a factor in ovarian neoplasia? Lancet $1971 ;$ ii: 163.

2 Cruickshank DJ. Aetiological importance of ovulation in epithelial ovarian cancer: a population based study. $B M 71990 ; 301: 524-5$.

3 Potashink G, Insler V, Meizner I. Frequency, sequence, and side of ovulation in women menstruating normally. $B M \mathcal{F} 1987 ; 294: 219$.

4 Slone D, Shapiro S, Miettinen OS. Case-control surveillance of serious illnesses attributable to ambulatory drug use. In: Colombo F, Shapiro S, Slone D, et al. eds. Epidemiological evaluation of drugs. Littleton, Massachusetts: PSG Publishing, 1977:59-74.

5 Snedecor GW, Cochran WG. Statistical methods. 6th ed. Ames, Iowa: Iowa State University Press, 1967:211.

(Accepted 20 August 1991)

\section{School attendance as a factor in deliberate self poisoning by $12-15$ year old adolescents}

\author{
L McGibben, C G Ballard, S Handy, \\ W R Silveira
}

Department of Psychiatry, Walsgrave Hospital, Coventry CV2 2DX

L McGibben, MRCPSYCH, senior registrar in child and adolescent psychiatry

$\mathrm{C} \mathrm{G}$ Ballard, $\mathrm{MB}$, registrar in psychiatry

S Handy, MRCPSYCH, registrar in psychiatry

W R Silveira, MRCPSYCH, consultant child and family psychiatrist

Correspondence to: Dr McGibben.

$B M 7$ 1992;304:28

Published reports on deliberate self poisoning among school age adolescents are scarce. We found only one study, in North America, discussing the importance of the school term as a possible risk factor. ${ }^{1}$ We studied the influence of school terms on deliberate self poisoning among schoolchildren from Coventry.

\section{Subjects, methods, and results}

We studied the medical records of all schoolchildren aged 12-15 in Coventry who had been admitted to hospital for deliberate self poisoning and hence referred for child psychiatric assessment. The completeness of data was assessed by cross checking the records by name and date with the list in the hospital admissions unit and with discharge summaries from paediatric wards.

Details of the dates of school terms were obtained from Coventry education department, and the rates of hospital admission for deliberate self poisoning were calculated per 1000 schoolchildren aged 12-15 per year for school terms and holidays. The relative risk of adolescents being admitted for deliberate self poisoning during school terms compared with during holidays and its $95 \%$ confidence interval were adjusted for the length of school holidays and terms. The various school holidays were compared by the same method.

The average number of $12-15$ year olds in Coventry during $1982-90$ was 18265 . Of these, 380 were admitted to hospital for deliberate self poisoning, $340(89 \%)$ having been referred to the child psychiatric services.

The $95 \%$ confidence intervals of the relative risk showed that there were significantly more hospital admissions during school terms than holidays (table). There were also significantly fewer admissions during the Christmas and summer holidays than during school term time, and there was a non-significant trend for

Rates of deliberate self poisoning and relative risks of its occurring during school terms among adolescents aged 12-15 in Coventry, 1982-90

\begin{tabular}{|c|c|c|}
\hline & $\begin{array}{c}\text { Rate } \\
\text { (per 1000/year) }\end{array}$ & $\begin{array}{c}\text { Relative risk } \\
\text { (95\% confidence interval) } \\
\text { during school term }\end{array}$ \\
\hline School term $(n=292)$ & $2 \cdot 86$ & \\
\hline Overall ${ }^{\star}(n=48)$ & 1.06 & $2.73(1.68$ to 4.66$)$ \\
\hline Christmas $(n=1)$ & 0.13 & $22 \cdot 23(7 \cdot 5$ to $395 \cdot 4)$ \\
\hline Easter $(n=14)$ & 1.94 & $1.49(0.97$ to 2.24$)$ \\
\hline Summer $(n=25)$ & $1 \cdot 27$ & $2 \cdot 28(1.40$ to \\
\hline
\end{tabular}

${ }^{\star}$ Including half term holidays. fewer admissions during the Easter holidays. When the different holiday periods were compared there were fewer admissions during the Christmas holidays than during either the Easter holidays (relative risk 14.92, 4.95 to 265.07$)$ or the summer holidays $(9.77,3.13$ to 170.72); there was also a non-significant trend for fewer admissions during the summer holidays than the Easter holidays.

\section{Comment}

As almost $90 \%$ of the adolescents in our study were referred for child psychiatric assessment we consider that the medical records gave a sufficiently reliable estimate of deliberate self poisoning among $12-15$ year old adolescents.

We chose an upper age limit of 15 because after 16 a young person is exposed to a more adult environment, with different expectations, responsibilities, and pressures from those of childhood. Also, 16 was the lower age limit in studies of parasuicide in adults. ${ }^{2}$

We found appreciable differences between the rates of deliberate self poisoning during school terms and holidays, the rate of admission being lowest during the Christmas and summer holidays. We tested seven comparisons for significance, which increases the risk of a spurious positive result. Most of the significant differences were, however, substantially above the conventional $95 \%$ level.

The data suggest that two main factors are operating. The larger is the influence of Christmas holidays in substantially reducing the rate and the smaller the direct influence of school attendance in increasing it. Possible risk factors that may increase the risk during school terms are the stress of school work, the competitive nature of much schooling, difficulties in fitting into a peer group, and bullying. Teachers' vigilance may have led to a slight increase in referral rates during school terms but it was probably not a major confounding factor. Alternatively, school terms may coincide with a seasonal variation. The data did not suggest a spring or autumn peak other than that limited to school holidays. This absence of seasonal variation is consistent with other data. ${ }^{3}$

The reduction in risk during the Christmas holidays may reflect the strength of family cohesion then. Both factors favour a sociological rather than a biological explanation and support the view that holiday times are a time of reduced sense of isolation ${ }^{4}$ and of enhanced family purpose.

We thank Dr $\mathrm{R} N$ Chithiramohan, senior registrar in psychiatry, for his help in preparing the manuscript.

1 Christoffel KK, Marcus D, Sagerman S, Bennett S. Adolescent suicide and suicide attempts: a population study. Pediatr Emerg Care 1988;4:32-40.

2 Masterton G. Monthly and seasonal variation in parasuicide. Br f Psychiatry 1991;158:155-7.

3 Papathomopoulos E, Vlachos P, Kalamara D, Papadatos C. Suicidal attempts by ingestion of various substances in 2050 children and adolescents in Greece. Can I Psychiatry 1989;34:205-10.

4 Durkheim E. Suicide: a study in sociology. London: Routledge and Kegan Paul, 1952. (Translated by J Spaulding and C Simpson.) 